\title{
Influence of breed, milk production, season, and ambient temperature on dairy cow reticulorumen temperature
}

\author{
D. Liang, ${ }^{*}$ C. L. Wood,† K. J. McQuerry,† D. L. Ray, ${ }^{*}$ J. D. Clark, ${ }^{*}$ and J. M. Bewley* \\ ${ }^{*}$ Department of Animal and Food Sciences, and \\ †Department of Statistics, University of Kentucky, Lexington 40546
}

\begin{abstract}
Automatic monitoring of core body temperature in dairy cattle could be useful for identification of illness, heat stress, general physiological stress, and estrus. The SmartBolus (TenXSys Inc., Eagle, ID) system used a reticulorumen bolus to automatically record and transmit dairy cow temperatures. The objective of this research was to characterize the influence of milk yield (MY), time of day, breed, ambient temperature (AT), and season on reticulorumen temperatures (RT) in lactating dairy cows. Continuous RT and AT were collected by SmartBolus transponders every 15 min (96 records per d) from 93 cows (65 Holstein, 18 crossbred, and 10 Jersey) for $615 \mathrm{~d}$. Mean $( \pm \mathrm{SD})$ daily RT, $\mathrm{AT}$, and MY were $40.14 \pm 0.32^{\circ} \mathrm{C}, 12.20 \pm 10.61^{\circ} \mathrm{C}$, and $33.85 \pm 8.67 \mathrm{~kg}$, respectively. The maximum and minimum RT were recorded at 2330 and $1000 \mathrm{~h}$, respectively. Ambient temperature increased RT. Summer RT was significantly greater than spring, fall, or winter RT. The effect of MY on RT varied by breed, season, and AT. Crossbred RT was significantly lower than Holstein RT after adjusting for MY. Crossbred RT responded less to increasing AT than did Holstein RT, potentially indicating improved heat tolerance among these crossbred dairy cows. Reticulorumen temperature increased more dramatically for cows with greater milk yield as AT increased, demonstrating that high-producing cows are more susceptible to heat stress than low-producing cows. These results could be useful in interpretation of automatic temperature system data, heat stress management, and genetic selection of heat-tolerant cows.
\end{abstract}

Key words: reticulorumen temperature, precision dairy farming, temperature monitoring, biosensor

\section{INTRODUCTION}

Body temperature is the most common and useful indicator of the interaction between a dairy cow and her physical environment (Nakamura et al., 1984).

Received December 30, 2012.

Accepted May 9, 2013.

${ }^{1}$ Corresponding author: jbewley@uky.edu
Changes in an animal's body temperature reflect the adjustment of thermal equilibrium to the ambient environment (Renaudeau et al., 2012). Generally, cow body core temperatures range from 38.6 to $39.2^{\circ} \mathrm{C}$ with daily variation of 0.8 to $1.8^{\circ} \mathrm{C}$ (Piccione and Refinetti, 2003). The lowest body temperatures occur during morning and early afternoon, and the highest temperatures occur during late night and early morning (Bitman et al., 1984). Lefcourt and Adams (1998) observed maximum and minimum body temperatures at 2323 and $1550 \mathrm{~h}$, respectively. In another study, the daily maximum body temperature was significantly greater than the daily minimum body temperature (Ipema et al., 2008), which demonstrated that the diurnal temperature difference was significant. Core body temperature is influenced by health and physiological status, ambient temperature, water intake, feed intake, parity, time relative to being milked, and season (Araki et al., 1984; Lefcourt and Adams, 1998; Bewley et al., 2008; Collier et al., 2012). Cow body temperature increases after feeding and decreases after milking (Araki et al., 1984; Bitman et al., 1984). Reticulorumen temperatures decrease after water intake and return to baseline temperature within 0.3 to $3.5 \mathrm{~h}$ (Cunningham et al., 1964; Yamada et al., 2001; Bewley et al., 2008). Lactating cows have greater body temperatures than dry cows, and increasing milk production increases body temperature (Araki et al., 1984; West, 2003). Dairy cows are sensitive to high ambient temperatures because of the high metabolic heat production and decreased feed intake during heat stress, which results in reduced rumen fermentation and milk yield (Collier et al., 2012). Heat stress begins when evaporative heat release is no longer enough to cool the cow down (Kadzere et al., 2002). The response of body temperature to ambient temperature may be useful in determining strategies of heat stress management (Al-Haidary et al., 2001).

Manual collection of rectal temperatures is the most common method of obtaining body temperatures in practice because of ease of measurement and low purchase costs of rectal thermometers (Hicks et al., 2001; Aalseth, 2005). However, this process is labor intensive, time consuming, influenced by presence or absence of feces, and may result in rectal injuries. Furthermore, 
because restraining animals to collect temperature data by manual means may cause stress that alters temperature, a reliable method of collecting temperatures without human intervention is likely to provide a more accurate measure of temperature in dairy cattle (Hahn et al., 1990; Prendiville et al., 2002). Firk et al. (2002) suggested that the utility of a cow temperature monitor was highly related to its measuring location. Common temperature monitoring locations included the rectum, ear (tympanic), vagina, reticulorumen, intraperitoneal cavity, and udder (milk). Hahn et al. (1990) supported using internal rather than external body temperature to reflect body temperature changes due to ambient temperature. Internal temperature measurement locations have advantages compared with external locations, because they are isolated from outside factors and the in vivo location allows continuous temperature measuring (Sievers et al., 2004). Thus, reticulorumen temperature could be an effective measure of deep core body temperature (Hicks et al., 2001; Prendiville et al., 2002; Bewley et al., 2008; Small et al., 2008). However, because of the activity of heat-producing rumen microorganisms, ruminal or reticular temperatures are generally about $0.5^{\circ} \mathrm{C}$ greater than core body temperatures (Bitman et al., 1984; Hicks et al., 2001; Prendiville et al., 2002). The SmartBolus (TenXSys Inc., Eagle, ID) system uses a reticulorumen bolus to automatically record and transmit cow temperatures. The objective of this research was to characterize the influence of milk yield (MY), time of day, breed, ambient temperature (AT), and season on reticulorumen temperatures (RT) in lactating dairy cows.

\section{MATERIALS AND METHODS}

\section{Data Collection}

This research was conducted using 93 cows $(65$ Holstein, 18 crossbred, and 10 Jersey) at the University of Kentucky Coldstream Research Dairy Farm (Lexington). Breed composition of crossbred cows included 7 Holstein $\times$ Jersey, 5 Brown Swiss $\times$ Holstein $\times$ Jersey, and 8 Scandinavian $\times$ Holstein $\times$ Jersey. All cows were housed in freestalls with $1 \mathrm{~h}$ of access to a pasture exercise lot each day. Fans were provided in the holding pen and in the freestall barns, and sprinklers were placed above the feedbunk. Cows were milked twice daily at 0430 and $1530 \mathrm{~h}$, and were fed a 17\% CP TMR, consisting of corn silage, alfalfa haylage, cottonseed, ground corn, soybean meal, distillers grains, and a mineral mix (with specific feedstuff amounts varying slightly throughout the study) at 0300 and $1300 \mathrm{~h}$. Reticulorumen temperatures were collected from SmartBolus transponders (TenXSys Inc.) every 15 min from November 06, 2009, to July 14, 2011. The SmartBolus system uses an active electronic bolus (11 cm long, 3.3 $\mathrm{cm}$ in diameter), which remains in the reticulorumen of the cow and transmits data to a computer via radio using repeaters. Another SmartBolus was placed 140 $\mathrm{cm}$ above the ground, on the east-side wall in a barn $\left(38^{\circ} 6^{\prime} 36^{\prime \prime} \mathrm{N}, 84^{\circ} 30^{\prime} 55^{\prime \prime} \mathrm{W}\right.$, altitude: $680 \mathrm{~m}$ above sea level) on the dairy farm during the same period to collect ambient temperature data.

In this project, spring was defined as March 20 to June 20; summer was defined as June 21 to September 21, fall was defined as September 22 to December 20, and winter was defined as December 21 to March 19. Test-day milk production data was obtained from PCDart (Dairy Records Management System, Raleigh, NC). Daily milk production (MY) was predicted from DHIA test-day data through extrapolation by weighting the number of days between 2 test days with milk production from the 2 associated test days. Daily milk production between calving and first test day were set to the first test-day milk production; daily milk production for the days after last test days were set to the last test-day milk production.

\section{Statistical Analysis}

The raw data included all recorded RT for the study cows for the days when their boluses were functioning and transmitting properly. The raw $\mathrm{RT}(\mathrm{n}=1,646,145)$ data were edited to remove erroneous reads and temperatures potentially influenced by water intake by removing $\mathrm{RT}<38.3^{\circ} \mathrm{C}$, which was based on previous experience with RT. The range used to remove temperatures affected by water intake was selected based on published estimates of reticulorumen temperatures from Bewley et al. (2008), and the critical temperature $\left(38.3^{\circ} \mathrm{C}\right)$ in this study was $3 \mathrm{SD}$ lower than the mean, considered as the lower confident interval limit of reticulorumen temperature without water intake effect. Then, extreme quarterly RT were removed by eliminating any temperature $<3 \mathrm{SD}$ or $>3 \mathrm{SD}$ from each individual cow's 28-d rolling average RT to exclude the effect of estrus or disease. Temperatures recorded during the dry period and when DIM $>400$ were not included in the analysis. The SORT and GLM procedures of SAS version 9.3 (SAS Institute Inc., Cary, $\mathrm{NC}$ ) were used to find the maximum and minimum RT to describe the diurnal rhythm of RT with (season) and without (overall) seasonal effects considered. The overall diurnal rhythm was the RT pattern in 24 $\mathrm{h}$ with 15-min intervals using the average $\mathrm{RT}$ for each recording time point. The seasonal diurnal rhythm was 
the RT pattern in $24 \mathrm{~h}$ with 15-min intervals using the average RT at each recording time point within 4 seasons separately.

The MEANS procedure of SAS version 9.3 (SAS Institute Inc.) was used to calculate the average daily RT and AT among all remaining temperatures within each cow day. The mean temperature among each day's 96 AT recordings was classified as the mean daily ambient temperature (DAT), and the average daily RT was classified as the mean daily reticulorumen temperature (DRT). Each cow's DRT was filtered by removing the days with DRT $<2$ or $>2$ SD from each individual cow's 28-d rolling average DRT to exclude outliers and extreme records. After these edits, 13,409 cow-day observations remained for 93 cows (65 Holstein, 18 crossbred, and 10 Jersey).

Two generalized linear models with repeated measures were constructed to describe DRT using the MIXED procedure of SAS version 9.3 (SAS Institute Inc.). One model focused on seasonal differences in RT of cows within breed over time. The DAT data were not included in the first model. In the second model, DAT, rather than season, was included, to explain the relationship between DAT and DRT of cows within breed over time. All main effects were kept in each model, regardless of significance level. Interactions were in- cluded in the models when significant at $P<0.05$ using backward elimination. Fixed effects for breed (Holstein, crossbred and Jersey), season (spring, summer, fall, and winter), and MY, along with 2-way interactions and 3-way interactions, were included in the first model to describe the seasonal changes in DRT:

$$
\begin{gathered}
\text { DRT }_{i j k l}=\text { Breed }_{i}+M Y_{k l}+\text { Season }_{j}+\text { Breed }_{i} \\
\times \text { MYl }_{k l}+\text { Season }_{j} \times M Y_{k l}+\text { Breed }_{i} \times \text { Season }_{j} \\
\quad+\text { Breed }_{i} \times \text { Season }_{j} \times M Y_{k l}+\delta_{k}+\varepsilon_{i j k l},
\end{gathered}
$$

where $i=$ Holstein, Jersey, or crossbred; $j=$ spring, summer, fall, or winter; $M Y_{k l}=$ daily milk production for the $k$ th cow at the lth time point; $\delta_{k}=$ random cow effect; and $\varepsilon_{i j k l}=$ autoregressive(1) process.

Fixed effects for breed and covariables for DAT and MY, along with 2-way interactions, were included in the second model. The relationship between DAT and DRT was not linear (Figure 1):

$$
\begin{aligned}
& D R T_{i k l}=\text { Breed }_{i}+M Y_{k l}+D A T_{k l}+\text { Breed }_{i} \\
& \times M Y_{k l}+\text { Breed }_{i} \times D A T_{k l}+M Y_{k l} \times D A T_{k l} \\
& +D A T_{k l}^{2}+D A T_{k l}^{3}+D A T_{k l}^{4}+\delta_{k}+\varepsilon_{i j k l}
\end{aligned}
$$

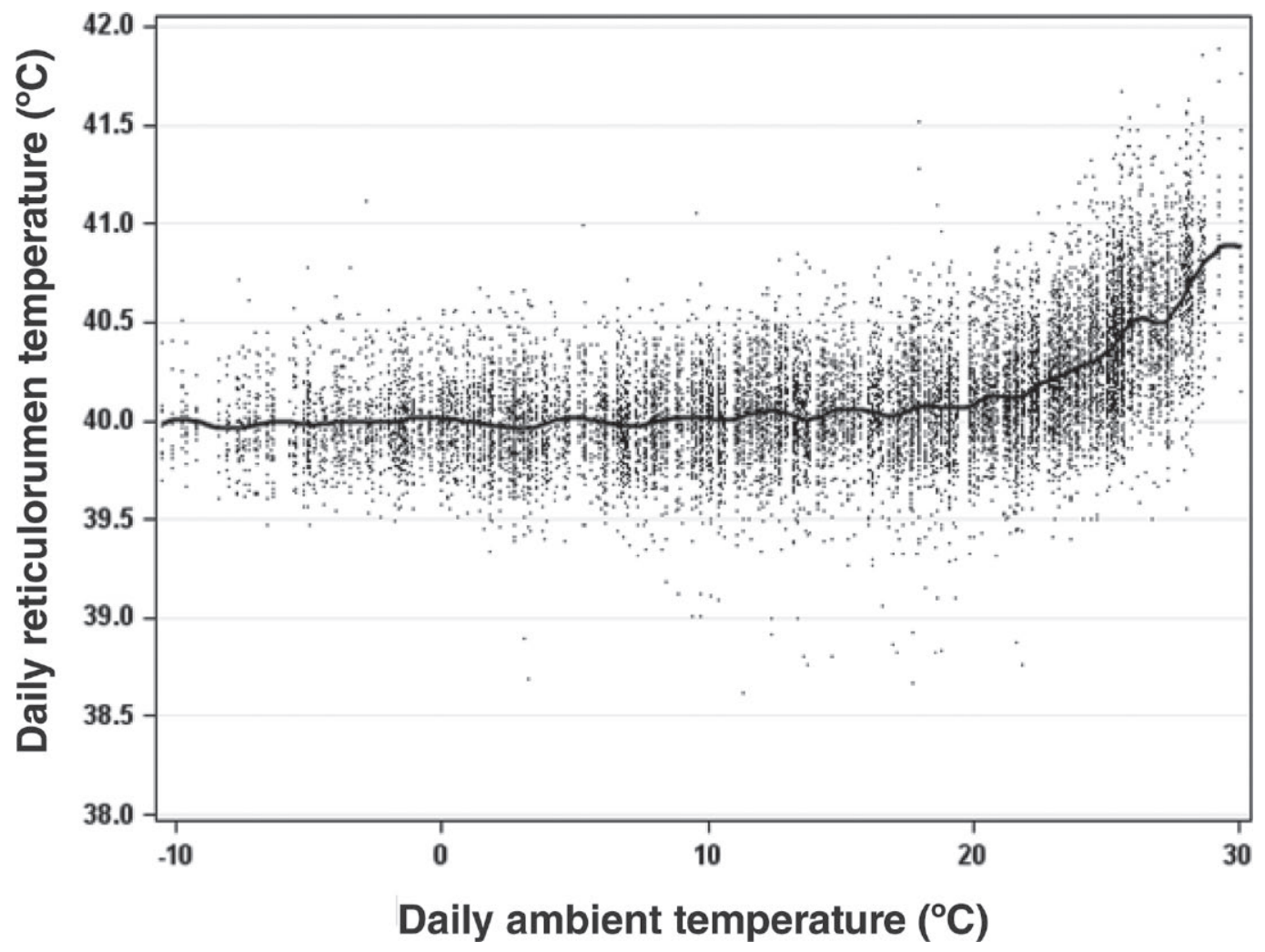

Figure 1. Relationship between daily ambient temperature (DAT) and daily reticulorumen temperature (DRT). 
where $i=$ Holstein, Jersey, or crossbred; $D A T_{k l}=$ daily reticulorumen temperature for the $k$ th cow at the $l$ th time point; $\delta_{k}=$ random cow effect; and $\varepsilon_{i j k l}=$ autoregressive(1) process.

\section{RESULTS AND DISCUSSION}

\section{Diurnal RT Rhythm}

Overall mean RT was $40.14^{\circ} \mathrm{C}$, ranging from 38.62 to $41.89^{\circ} \mathrm{C}$; the mean $\mathrm{RT}$ was greater than the 38.6 to $39.2^{\circ} \mathrm{C}$ reported by Piccione and Refinetti (2003). The greater temperatures observed in this study may be partially explained by the location of the temperature monitoring device in the reticulorumen and the strict criteria used to remove temperatures potentially affected by water intake. The overall diurnal maximum and minimum RT were recorded at 2330 and $1000 \mathrm{~h}$, respectively. Spring, summer, fall, and winter maximum RT were recorded at 1830, 1430, 0715, and 0730 $\mathrm{h}$, respectively, whereas seasonal minimum RT were recorded at 1000, 0945, 1030, and $1030 \mathrm{~h}$, respectively (Figures 2, 3, and 4). In the fall and winter, maximum RT was recorded in the morning, whereas in the summer and spring maximum RT was recorded in late afternoon or early evening. This difference likely reflects the greater influence of AT on RT with increasing AT. In agreement with Lefcourt et al. (1999) and Collier et al. (2012), daily maximum RT was significantly greater than daily minimum RT in all seasons $(P<0.01)$. The entire-level maximum and minimum AT were observed at 1800 and $0745 \mathrm{~h}$, respectively (Figures 2 and 4).

\section{Season}

Mean ( $\pm \mathrm{SD})$ daily RT during spring, summer, fall, and winter were $40.10 \pm 0.29,40.39 \pm 0.36,40.09 \pm$ 0.23 , and $40.00 \pm 0.21^{\circ} \mathrm{C}$, respectively. Summer DRT least squares means $(\mathrm{n}=2,898)$ was greater than spring $(\mathrm{n}=5,489)$ and winter $(\mathrm{n}=3,288)$ DRT $(P<0.01)$. Spring DRT was greater than winter DRT $(P<0.01)$. However, fall DRT $(\mathrm{n}=1,734)$ was not significantly different from spring, summer, or winter DRT $(P=$ $0.51,0.55$, and 0.60, respectively; Figure 5).

Previous studies described a "seasonal drift" phenomenon of deep body temperature on dairy cows (Zartman and Dealba, 1982; Fordham et al., 1988). In the current experiment, season affected DRT considerably. Summer DRT was the highest, followed by spring and winter; fall DRT was not significantly different from any of the other seasons. The mean, maximum, and minimum summer RT were $0.40,0.39$, and $0.21^{\circ} \mathrm{C}$ greater than

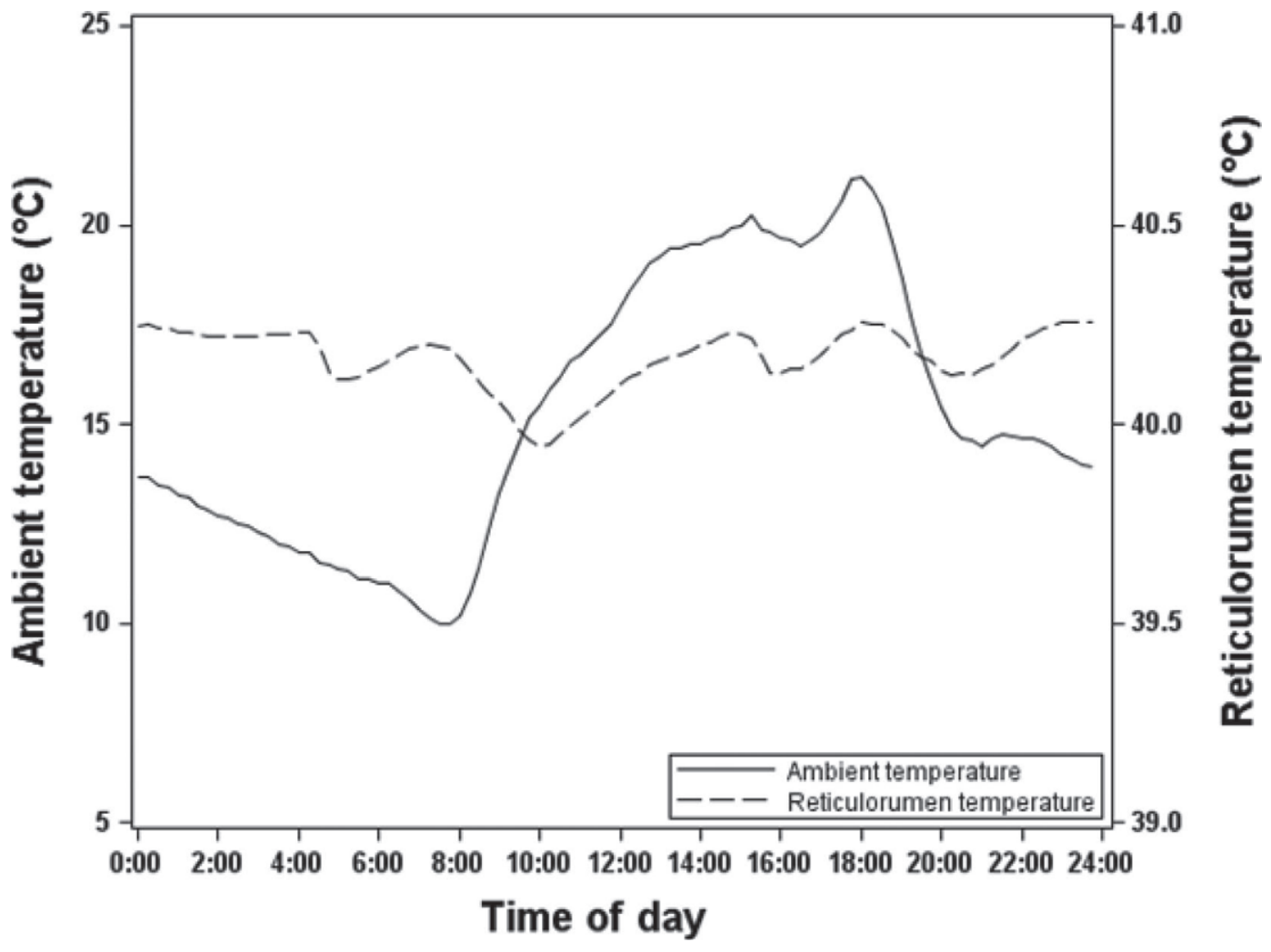

Figure 2. Overall diurnal rhythms of reticulorumen temperature relative to feeding and milking times. 


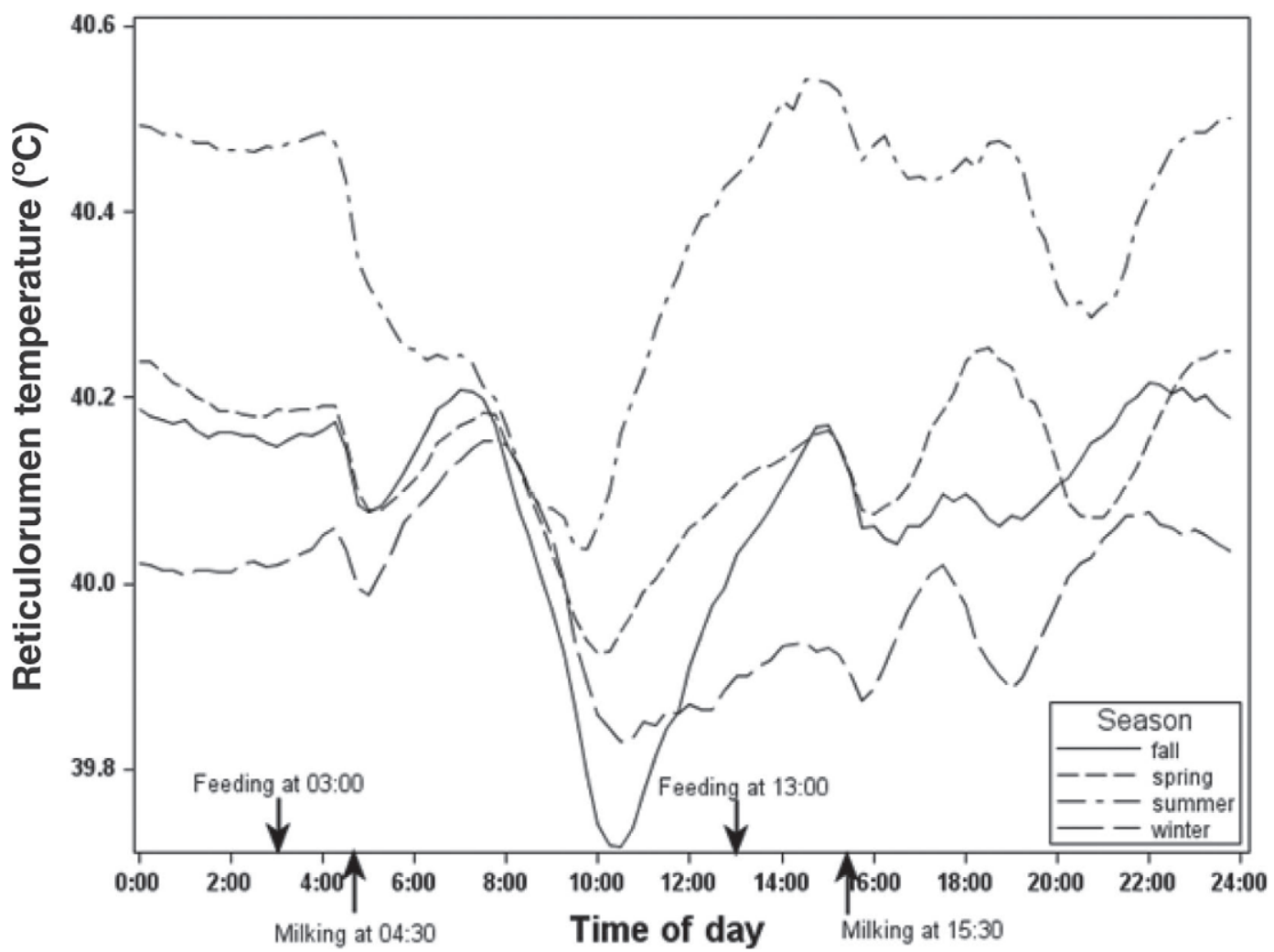

Figure 3. Diurnal rhythms of reticulorumen temperature by season relative to feeding and milking times.

those in winter, respectively. The differences in RT by season observed in this study partially reflect the effect of changes in AT on RT. However, these changes may also reflect a biological change in core body temperature associated with changing seasons. The seasonal body temperature baseline may be useful for interpretation of differences in body temperature used for cow management by season. At minimum, these differences indicate the need to adjust thresholds used for management purposes by season.

\section{Breed}

Physiological responses to ambient conditions are breed-specific because of body size, skin color, sweating rate, respiration rate, and heat production (Finch, 1986; Kadzere et al., 2002). Mean daily $( \pm S D)$ RT of Holstein, Jersey, and crossbred were $40.17 \pm 0.33,40.04$ \pm 0.25 , and $40.05 \pm 0.29^{\circ} \mathrm{C}$, respectively. Crossbred DRT were lower than Holstein DRT $(P<0.01$; Figure $6)$, although this relationship varied by MY and DAT $(P<0.01$; Tables 1 and 2, Figure 1). In summer, Jersey DRT was lower than Holstein DRT $(P<0.01)$. These differences in RT are adjusted for differences in milk yield.
Finch (1986) found that Bos taurus had greater RT than Bos indicus. Among B. taurus, Holstein-Friesian cows were more sensitive to heat stress than Jersey (Sharma et al., 1983). Higher RT suggest greater metabolic heat production (Srikandakumar and Johnson, 2004). Breed affects DRT because of different physiological activities, heat production, coat layer and color, body size, and body surface area (Finch, 1986; Kadzere et al., 2002; Berman, 2003). In this study, Holstein DRT was greater than that of crossbreds in all seasons and greater than that of Jersey only during the summer. The influence of breed on DRT also depended on milk production and ambient temperature (or season). These results suggest that crossbred cows may be more heat tolerant than Holstein cows, possibly indicative of hybrid vigor. Differences in DRT were not observed between Jersey and Holstein or Jersey and crossbred cows, although this difference may be partially explained by the limited number of Jerseys available for the study.

\section{Daily Milk Production}

Mean $( \pm \mathrm{SD})$ daily MY was $33.85 \pm 8.67 \mathrm{~kg}$, ranging from 4.18 to $56.77 \mathrm{~kg}$. Mean $( \pm \mathrm{SD}) \mathrm{MY}$ of Holstein, Jersey, and crossbred were $35.27 \pm 8.44,23.25 \pm 5.78$, 


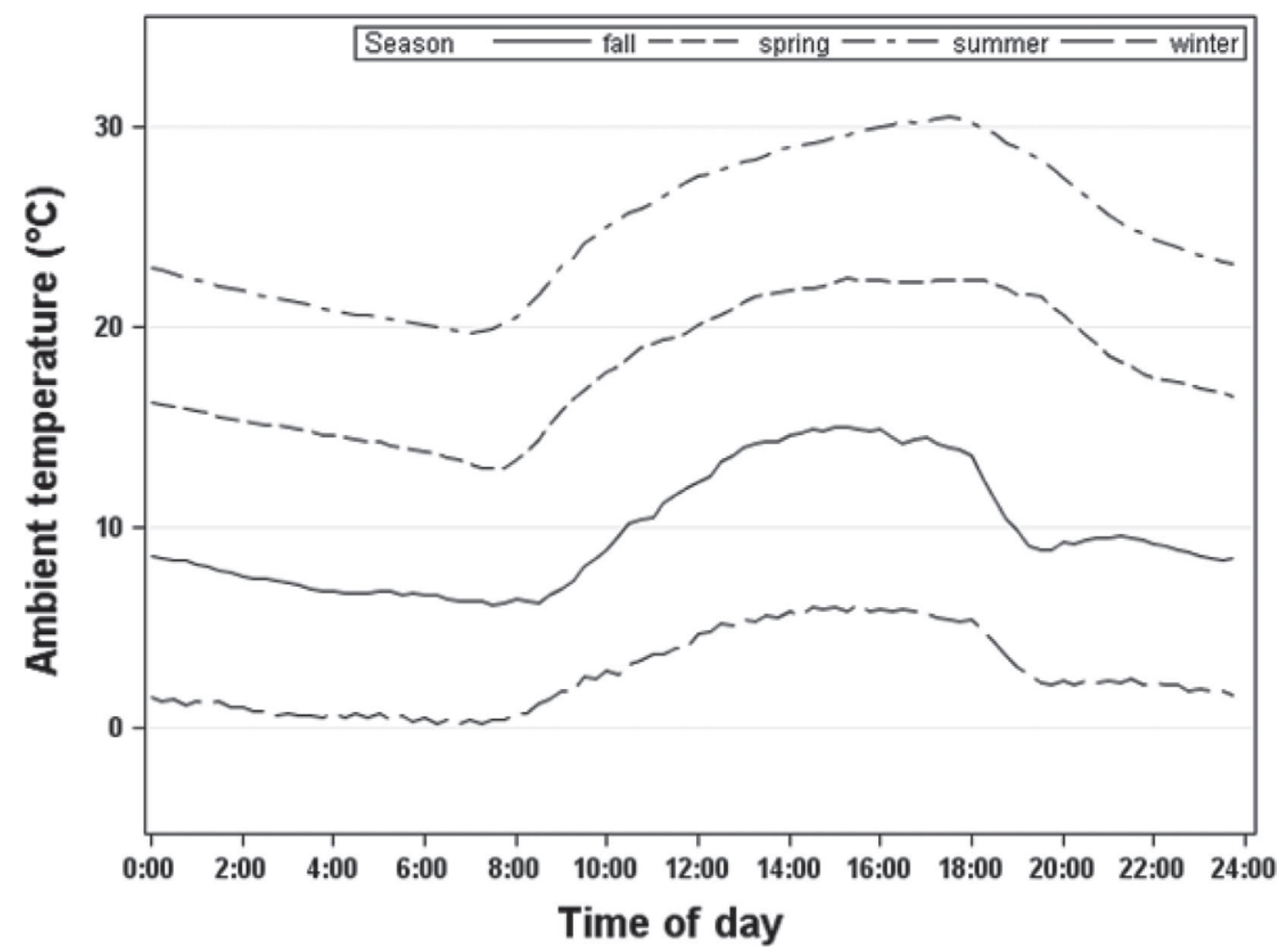

Figure 4. Diurnal rhythms of ambient temperature by season.

and $31.72 \pm 7.80 \mathrm{~kg}$, respectively. Mean $( \pm \mathrm{SD}) \mathrm{MY}$ during spring, summer, fall, and winter were $34.29 \pm$ $8.65,30.89 \pm 6.56,32.48 \pm 9.40$, and $36.39 \pm 9.07$ $\mathrm{kg} / \mathrm{d}$, respectively. Milk production did not affect DRT directly $(P=0.23$, Table $1 ; P=0.22$, Table 2$)$. The effect of MY on DRT depended on breed, season, or DAT $(P \leq 0.01$; Tables 1 and 2$)$.

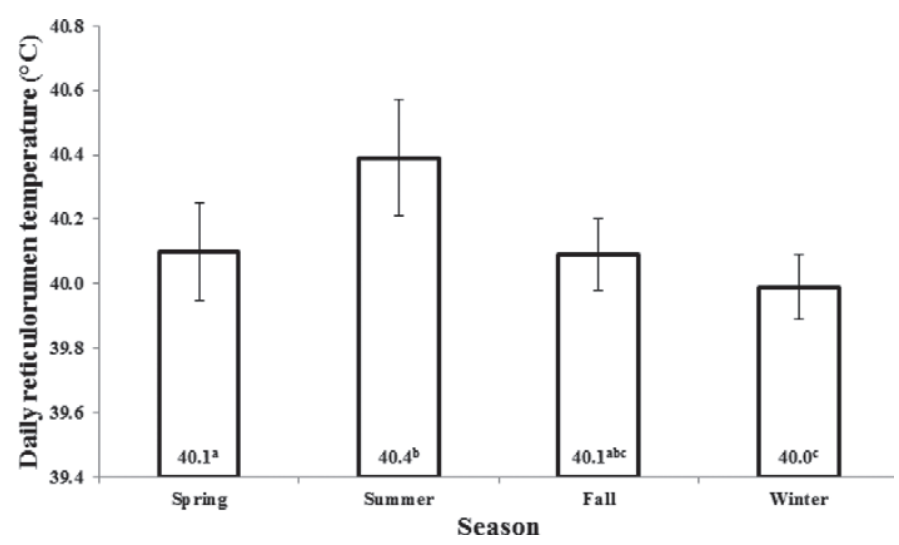

Figure 5. Mean daily reticulorumen temperatures by season $($ spring $=$ March 20 to June 20; summer $=$ June 21 to September 21, fall $=$ September 22 to December 20 , and winter $=$ December 21 to March 19). ${ }^{a-c}$ Temperatures among seasons with different letters were significantly different $(P<0.05)$.
Increased milk production can elevate body temperature (Igono et al., 1985), and high-producing cows (31.6 $\mathrm{kg} / \mathrm{d}$ ) produce $48.5 \%$ more heat than dry cows (Purwanto et al., 1990), which leads to greater body temperature. The increased feed intake required to support increased milk production leads to greater heat generation, which leads to greater RT. Conversely, greater

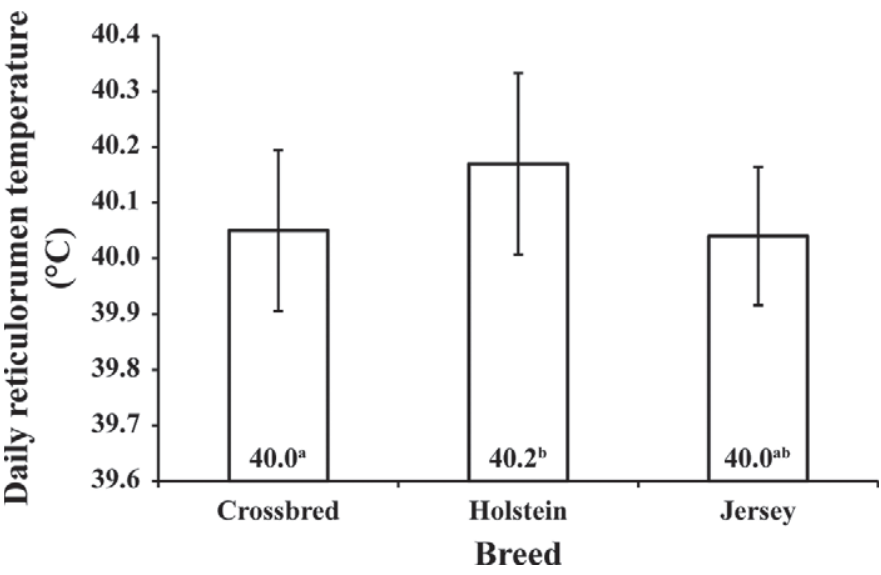

Figure 6. Mean daily reticulorumen temperatures by breed $(7$ Holstein $\times$ Jersey, 5 Brown Swiss $\times$ Holstein $\times$ Jersey, and 8 Scandinavian $\times$ Holstein $\times$ Jersey). ${ }^{\mathrm{a}, \mathrm{b}}$ Temperatures among breeds with different letters were significantly different $(P<0.05)$. 
Table 1. Test of significance of factors influencing daily mean reticulorumen temperature for model using season to represent ambient conditions $^{1,2}$

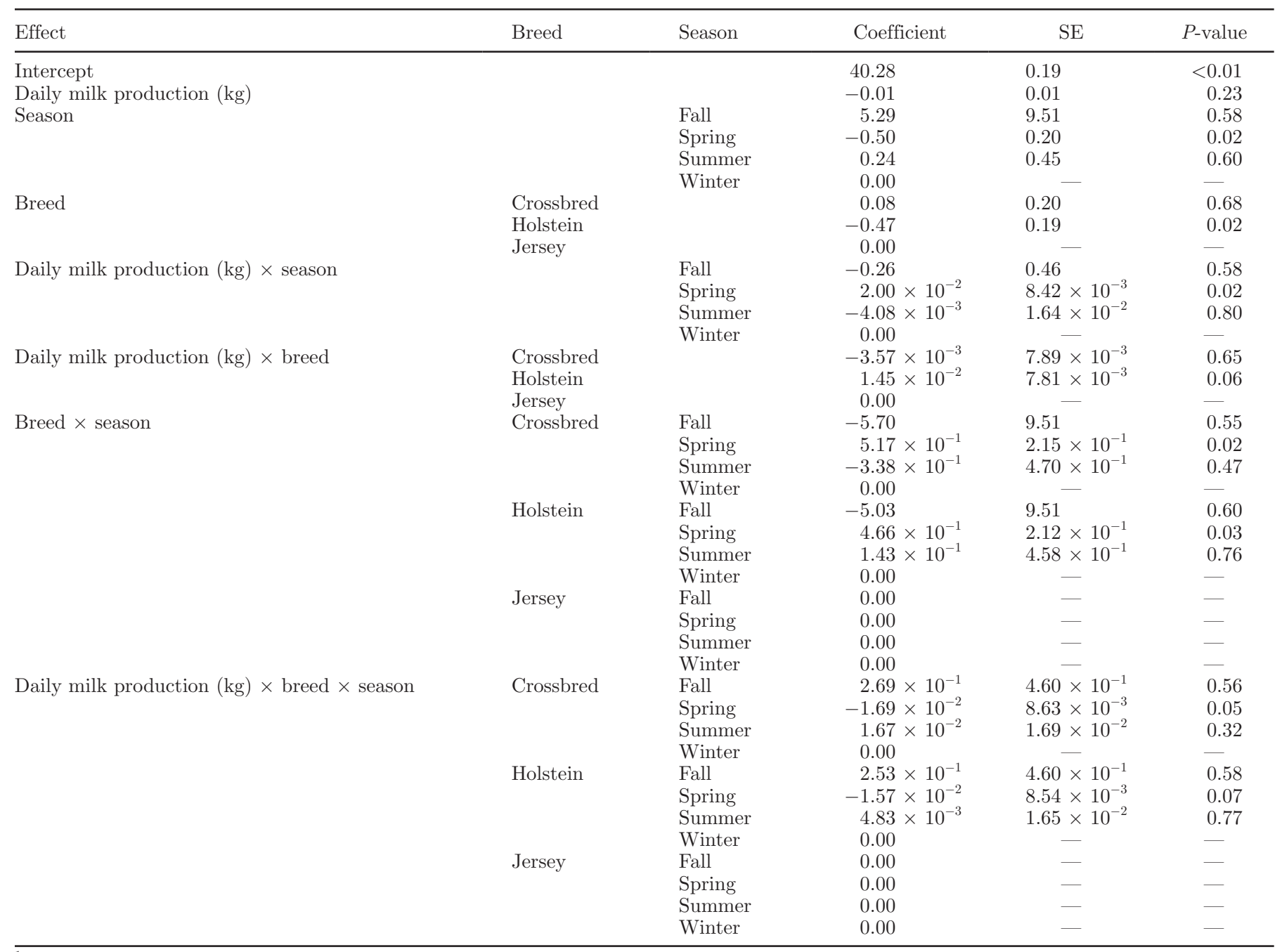

${ }^{1}$ Breeds defined as crossbred, Holstein, or Jersey.

${ }^{2}$ Winter and Jersey were used as base in comparison.

body temperature has negative consequences on feed intake, feed digestion, and metabolism processes, which lead to inhibited milk production as a result (West, 2003). Based on the current results, more research is needed to explain the 2-way interaction between milk production and body temperature.

\section{Daily Ambient Temperature}

Mean $( \pm \mathrm{SD})$ DAT was $12.20 \pm 10.61^{\circ} \mathrm{C}$, ranging from -10.55 to $30.07^{\circ} \mathrm{C}$. Mean $( \pm \mathrm{SD})$ AT for spring, summer, fall, and winter were $17.52 \pm 6.36,24.71 \pm$ $2.58,8.15 \pm 7.85$, and $1.45 \pm 5.99^{\circ} \mathrm{C}$, respectively. Daily ambient temperature affected DRT directly $(P<0.01$, Table 2). As DAT was not related linearly with DRT, the increasing rate of DRT was more sensitive as AT increased: cow DRT was stable until DAT exceeded the upper critical temperature (UCT; Figure 1). This result demonstrated that cows were more sensitive in warmer conditions (Collier et al., 2012). The effect of DAT on DRT varied by breed and MY $(P<0.01$; Table 2, Figure 1).

$\boldsymbol{D A T} \times$ Breed. Crossbred DRT increased more slowly than Holstein DRT as DAT increased; Jersey DRT decreased slightly and then increased when DAT increased from -10 to $30^{\circ} \mathrm{C},(P<0.01$; Table 2 , Figure 7). In this study, Holstein had the highest DRT, followed by crossbred, and then Jersey, when AT exceeded the UCT $\left(23.9^{\circ} \mathrm{C}\right.$; Collier et al., 2012). Breeds differ in body size, metabolism rate, skin color, and surface area, all of which affect their heat generation and emission processes. In this study, crossbred cows showed 
Table 2. Test of significance of factors influencing daily mean reticulorumen temperature for model using ambient temperature (AT) to represent ambient conditions ${ }^{1}$

\begin{tabular}{|c|c|c|c|c|}
\hline Effect & Breed $^{2}$ & Coefficient & SE & $P$-value \\
\hline \multirow{2}{*}{ Breed } & Crossbred & 0.30 & 0.08 & $<0.01$ \\
\hline & Holstein & -0.16 & 0.08 & 0.04 \\
\hline Daily milk production $(\mathrm{kg})$ & & $3.87 \times 10^{-3}$ & $3.13 \times 10^{-3}$ & 0.22 \\
\hline Daily AT $\left({ }^{\circ} \mathrm{C}\right)$ & & $-9.63 \times 10^{-3}$ & $2.16 \times 10^{-3}$ & $<0.01$ \\
\hline Daily $\operatorname{AT}\left({ }^{\circ} \mathrm{C}\right) \times$ daily $\operatorname{AT}\left({ }^{\circ} \mathrm{C}\right)$ & & $2.59 \times 10^{-4}$ & $1.11 \times 10^{-4}$ & 0.02 \\
\hline Daily milk production $(\mathrm{kg}) \times$ breed & Crossbred & $-1.38 \times 10^{-2}$ & $3.16 \times 10^{-3}$ & $<0.01$ \\
\hline Daily milk production $(\mathrm{kg}) \times$ breed & Holstein & $6.04 \times 10^{-4}$ & $3.12 \times 10^{-3}$ & 0.85 \\
\hline Daily milk production $(\mathrm{kg}) \times$ breed & Jersey & 0.00 & - & - \\
\hline Daily AT $\left({ }^{\circ} \mathrm{C}\right) \times$ breed & Crossbred & $7.23 \times 10^{-3}$ & $1.82 \times 10^{-3}$ & $<0.01$ \\
\hline Daily AT $\left({ }^{\circ} \mathrm{C}\right) \times$ breed & Holstein & $1.18 \times 10^{-2}$ & $1.78 \times 10^{-3}$ & $<0.01$ \\
\hline Daily AT $\left({ }^{\circ} \mathrm{C}\right) \times$ breed & Jersey & 0.00 & - & - \\
\hline Daily milk production $(\mathrm{kg}) \times$ daily $\mathrm{AT}\left({ }^{\circ} \mathrm{C}\right)$ & & $1.24 \times 10^{-4}$ & $4.10 \times 10^{-5}$ & $<0.01$ \\
\hline
\end{tabular}

${ }^{1}$ Breeds defined as crossbred, Holstein, or Jersey.

${ }^{2}$ Jersey was used as base in the comparison.

potential for greater heat tolerance than did Holstein cows (Figure 7).

$\boldsymbol{D A T} \times \boldsymbol{M Y}$. Generally, high-producing cows had greater DRT than low-producing cows; and cows under warm environment ( $>\mathrm{UCT}$ ) had greater DRT than those in a cold environment (Figure 8). The DRT differences between high-producing and low-producing cows increased as AT increased $(P<0.01$; Table 2, Figure 8). As ambient temperature exceeds $10^{\circ} \mathrm{C}$, release of convective and radiant heat decreases and evaporative heat (released from the skin) increases (Berman, 2003). When ambient temperature exceeds the UCT, evaporation is not able to meet the demand of heat emission, and the cow's temperature regulation mechanism has

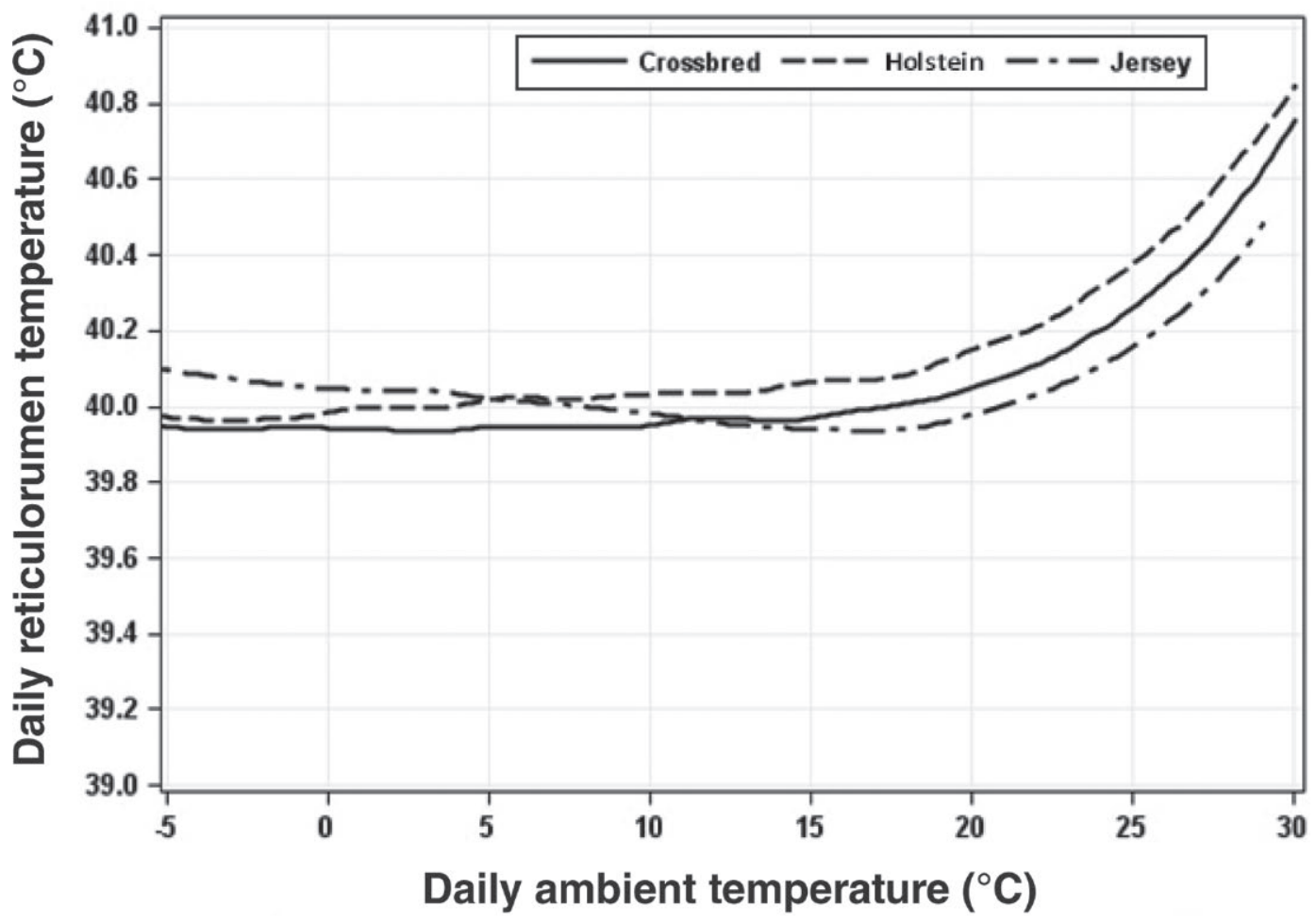

Figure 7. Relationship between daily ambient temperature and daily reticulorumen temperature by breed. 


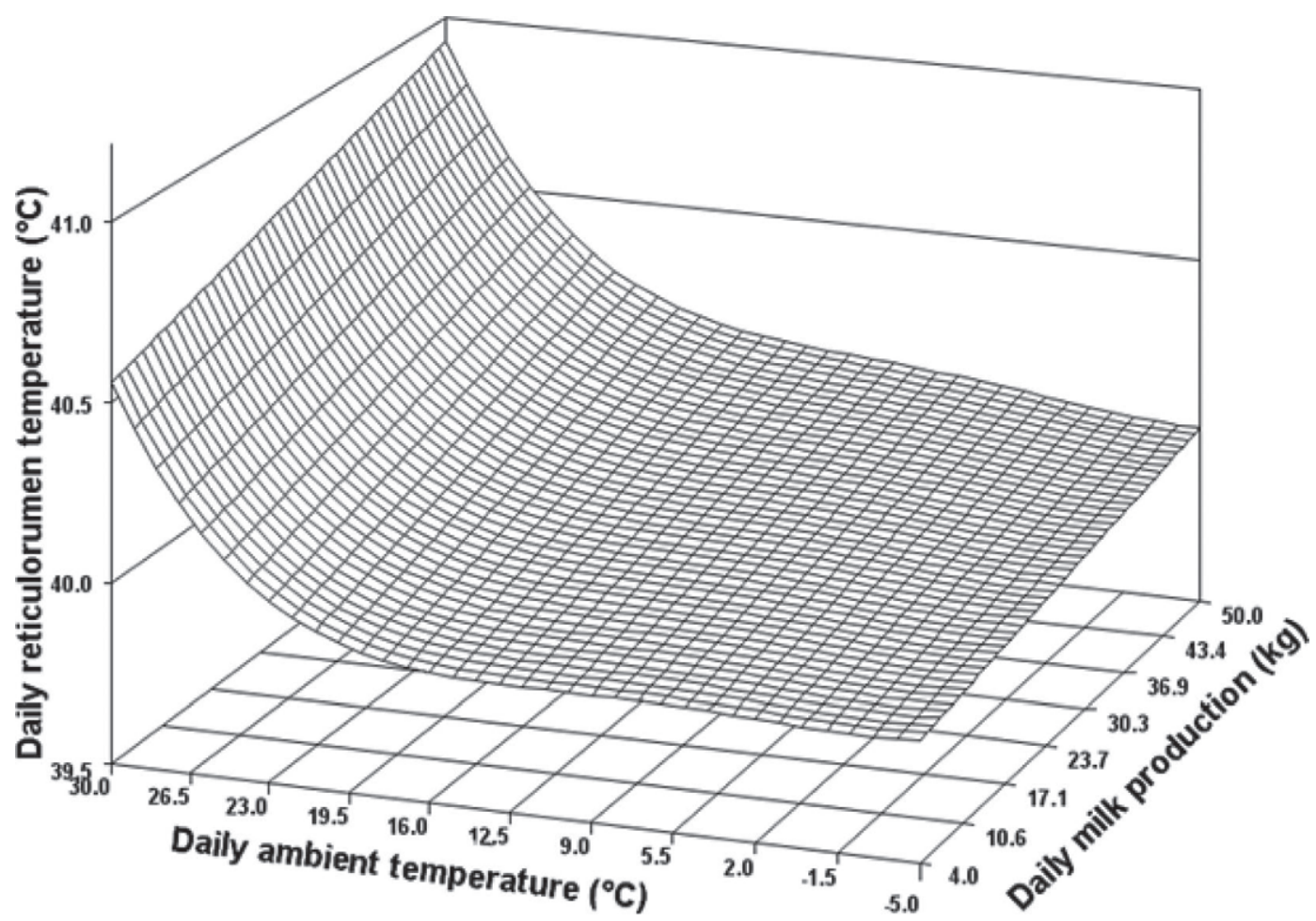

Figure 8. Relationships among daily ambient temperature, daily milk production, and daily reticulorumen temperature.

to increase body temperature to adapt to the external environment (Hahn et al., 1990).

According to Wheelock et al. (2010), milk production decreases during heat stress as a result of both reduction in feed intake and a shift in postabsorbtive metabolism (i.e., glucose and lipid metabolism). As indicated earlier, high-producing cows have greater RT, making it more difficult to maintain thermal equilibrium. High-producing cows are at greater risk of entering heat stress (Bianca, 1965; West, 2003; Renaudeau et al., 2012). Results from this study demonstrate how rapidly body temperatures increase with increasing AT (Figure 8), demonstrating the need to manage heat stress in dairy environments. Moreover, the nonlinear relationship between AT and RT demonstrates how sensitive cows are to changes in AT at greater temperatures.

\section{CONCLUSIONS}

Ambient temperature, milk production, and breed influence reticulorumen temperature. Crossbred cows may be more heat tolerant than Holstein cows, even after adjusting for differences in milk yield. These results provide new insight into cow body temperature and may be useful in heat stress management.

\section{ACKNOWLEDGMENTS}

The authors thank Joey Clark and staff at the University of Kentucky Coldstream Dairy Research Unit (Lexington) for their help in feeding, milking, and observing cows. We also thank Frank Riskey (TenXSys Inc., Eagle, ID) for his technical support. Finally, we thank Karmella Dolecheck, Elizabeth Eckelkamp, and Barbara Wadsworth (all from the University of Kentucky, Department of Animal and Food Sciences) for their help in editing this manuscript.

\section{REFERENCES}

Aalseth, E. 2005. Fresh cow management: What is important, what does it cost, and what does it return? Pages 1-12 in Proc. 7th Western Dairy Management Conf., Reno, NV. Kansas State University and Cooperative Extension Service, Manhattan.

Al-Haidary, A., D. E. Spiers, G. E. Rottinghaus, G. B. Garner, and M. R. Ellersieck. 2001. Thermoregulatory ability of beef heifers following intake of endophyte-infected tall fescue during controlled heat challenge. J. Anim. Sci. 79:1780-1788.

Araki, C. T., R. M. Nakamura, L. W. G. Kam, and N. Clarke. 1984. Effect of lactation on diurnal temperature patterns of dairy cattle in hot environments. J. Dairy Sci. 67:1752-1760.

Berman, A. 2003. Effects of body surface area estimates on predicted energy requirements and heat stress. J. Dairy Sci. 86:3605-3610.

Bewley, J. M., M. W. Grott, M. E. Einstein, and M. M. Schutz. 2008. Impact of intake water temperatures on reticular temperatures of lactating dairy cows. J. Dairy Sci. 91:3880-3887. 
Bianca, W. 1965. Reviews of the progress of dairy science. J. Dairy Res. 32:291-345.

Bitman, J., A. Lefcourt, D. L. Wood, and B. Stroud. 1984. Circadian and ultradian temperature rhythms of lactating dairy cows. J. Dairy Sci. 67:1014-1023.

Collier, R. J., L. W. Hall, S. Rungruang, and R. B. Zimbleman. 2012. Quantifying heat stress and its impact on metabolism and performance. Pages 74-83 in Proc. Florida Ruminant Nutrition Symp. University of Florida, Gainesville.

Cunningham, M., F. Martz, and C. Merilan. 1964. Effect of drinkingwater temperature upon ruminant digestion, intraruminal temperature, and water consumption of nonlactating dairy cows. J. Dairy Sci. 47:382-385.

Finch, V. A. 1986. Body temperature in beef cattle its control and dry and lactating dairy cows relevance to production in the tropics. J. Anim. Sci. 62:531-542.

Firk, R., E. Stamer, W. Junge, and J. Krieter. 2002. Automation of oestrus detection in dairy cows: A review. Livest. Prod. Sci. $75: 219-232$

Fordham, D. P., P. Rowlinson, and T. T. McCarthy. 1988. Oestrus detection in dairy cows by milk temperature measurement. Res. Vet. Sci. 44:366-374.

Hahn, G. L., R. A. Eigenberg, J. A. Nienaber, E. T. Littledike, and R. L. Hruska. 1990. Measuring physiological-responses of animals to environmental stressors using a microcomputer-based portable datalogger. J. Anim. Sci. 68:2658-2665.

Hicks, L. C., W. S. Hicks, R. A. Bucklin, J. K. Shearer, D. R. Bray, P. Soto, and V. Carvalho. 2001. Comparison of methods of measuring deep body temperatures of dairy cows. Pages 432-438 in Proc. Livestock Environment VI: Proc. 6th Int. Symp. ASAE. Am. Soc. Agric. Biol. Eng., St. Joseph, MI.

Igono, M. O., B. J. Steevens, M. D. Shanklin, and H. D. Johnson. 1985. Spray cooling effects on milk production, milk, and rectal temperatures of cows during a moderate temperate summer season. J. Dairy Sci. 68:979-985.

Ipema, A. H., D. Goense, P. H. Hogewerf, H. W. J. Houwers, and H. van Roest. 2008. Pilot study to monitor body temperature of dairy cows with a rumen bolus. Comput. Electron. Agric. 64:49-52.

Kadzere, C. T., M. R. Murphya, N. Silanikove, and E. Maltz. 2002. Heat stress in lactating dairy cows: A review. Livest. Prod. Sci. 77:59-91.

Lefcourt, A. M., and W. R. Adams. 1998. Radiotelemetric measurement of body temperature in feedlot steers during winter. J. Anim. Sci. 76:1830-1837.
Lefcourt, A. M., J. B. Huntington, R. M. Akers, D. L. Wood, and J. Bitman. 1999. Circadian and ultradian rhythms of body temperature and peripheral concentrations of insulin and nitrogen in lactating dairy cows. Domest. Anim. Endocrinol. 16:41-55.

Nakamura, R., C. Araki, N. Clarke, and L. Kam. 1984. Temperature telemetry studies in dairy cattle in hot climates. Pages 464-469 in Proc. National Conference on Agricultural Electronics Applications. American Society of Agricultural Engineers, St. Joseph, MI.

Piccione, G., and R. Refinetti. 2003. Thermal chronobiology of domestic animal. Front. Biosci. 8:258-264.

Prendiville, D., J. Lowe, B. Earley, C. Spahr, and P. Kettlewell. 2002. Radiotelemetry systems for measuring body temperature. Beef Prod. No. Ser. No. 57. Grange Research Centre, Tunsany, Ireland.

Purwanto, B. P., Y. Abo, R. Sakamoto, F. Furumoto, and S. Yamamoto. 1990. Diurnal patterns of heat production and heart rate under thermoneutral conditions in Holstein Friesian cows differing in milk production. J. Agric. Sci. 114:139-142.

Renaudeau, D., A. Collin, S. Yahav, V. de Basilio, J. Gourdine, and R. Collier. 2012. Adaptation to hot climate and strategies to alleviate heat stress in livestock production. Animal 6:707-728.

Sharma, A. K., L. A. Rodrigues, G. Mekonnen, C. J. Wilcox, K. C. Bachman, and R. J. Collier. 1983. Climatological and genetic effects on milk composition and yield. J. Dairy Sci. 66:119-126.

Sievers, A. K., N. B. Kristensen, H. J. Laue, and S. Wolffram. 2004 Development of an intraruminal device for data sampling and transmission. J. Anim. Feed Sci. 13:207-210.

Small, J. A., A. D. Kennedy, and S. H. Kahane. 2008. Core body temperature monitoring with passive transponder boluses in beef heifers. Can. J. Anim. Sci. 88:225-235.

Srikandakumar, A., and E. Johnson. 2004. Effect of heat stress on milk production, rectal temperature, respiratory rate and blood chemistry in Holstein, Jersey and Australian milking Zebu cows. Trop. Anim. Health Prod. 36:685-692.

West, J. W. 2003. Effects of heat-stress on production in dairy cattle. J. Dairy Sci. 86:2131-2144.

Wheelock, J. B., R. P. Rhoads, M. J. Vanbaale, S. R. Sanders, and L. H. Baumgard. 2010. Effects of heat stress on energetic metabolism in lactating Holstein cows. J. Dairy Sci. 93:644-655.

Yamada, A., M. Sutoh, and T. Imura. 2001. The changes of rumen temperature with grazing behavior in the daytime. Grassl. Sci. 47:491-493.

Zartman, D. L., and E. Dealba. 1982. Remote temperature sensing of estrous cycles in cattle. Anim. Reprod. Sci. 4:261-267. 